Szymon Nożyński i] http://orcid.org/0000-0003-3530-1797

Dolnośląska Szkoła Wyższa

Marek Okólski @ic http://orcid.org/0000-0001-8172-7428

Uniwersytet Wrocławski

\title{
MUZYKA BEZ NOŚNIKA? POWIETRZE, CHMURY I STRUMIENIE ORAZ CYFRY, TAŚMY I WINYLE W WALCE O PIERWOSŁUCH LUB ZAPOMNIENIE
}

Music without a (physical) medium? Air, clouds and streams vs CDs, tapes and vinyl in a struggle for listening or forgetting

\begin{abstract}
In the article the authors try to build a research reflection by means of a logical description of the result of self and technology - sound carriers/media, up to the extreme form, that is their disappearance, or distance from the listener/user. The authors show the influence of media on the organization of musical expression in the field of semiotics, technology and aesthetics.

The starting point of the article is a reflection on a fragment of the lyrics, which suggests a return of music to the air. The authors reconstruct the evolutionary path of sound carriers and reach the place where the air was the primary carrier. At the same time they analyze the contemporary face of technologically entangled air (as a carrier), which is no longer the air from the pre-industrial era, but rather a symbolic place where one can find wireless communication, the Internet or Bluetooth.

The article has a philosophical and technological character and serves primarily to consider the role of carriers in the current media reality in which, on the one hand, retro resentment is revived and, on the other hand, the form of streaming services takes over the market of music distribution. The contemporary listener, producer-consumer and remixer, modifies his behaviours, rituals and habitus of listening - the perception of sound.
\end{abstract}

Key words: music, streaming, vinyl, media, semiotics of popular music, air, wireless 
Nie gorsza, nie lepsza, odwieczna muzyka wraca do powietrza znika nośnik super wystarczy głośnik $i$ woofer

Nagranie fonograficzne stanowi coś na kształt skandalu filozoficznego - przekształca chwile w coś nieustannego, pędzi pod prąd jednokierunkową ulica o nazwie Czas ${ }^{2}$.

„Muzyka wraca do powietrza” - deklamuje Abradab w tekście piosenki umieszczonej na albumie z 2018 roku. Najprawdopodobniej artysta chciał w ten sposób zobrazować przemiany technologiczne dotyczące dystrybucji muzyki, która ewoluuje od nośników fizycznych do form udostępniania strumieniowego lub po prostu postaci niematerialnej. Skoro muzyka w ra ca do powietrza, oznacza to, że kiedyś już tam była - mówimy tu o czasach przednośnikowych. Sam nośnik zaś należy tutaj rozumieć jako fizyczny artefakt, na którym muzyka jest zapisana. W węższym, technologicznym rozumieniu i przyjętej perspektywie - mamy na myśli zakres czasowy, w którym powstały urządzenia rejestrująco-odtwarzające, mogące dźwięk utrwalić. Jednak powietrze, o którym piosenka traktuje, nie jest już tym samym powietrzem przednośnikowym, ale powietrzem wypełnionym komunikacją bezprzewodową, zdolną transportować dane. Warto zatem raz jeszcze wieloaspektowo przyjrzeć się wpływowi materialnych i niematerialnych nośników, zarówno na sam dźwięk, jak i jego percepcję oraz - w konsekwencji - kulturowo i technologicznie modyfikowane sposoby słuchania.

Muzyka już w swych pierwotnych formach była naznaczona wymiarem przestrzennym i czasowym, twórczość muzyczna sama w sobie wpływa intensywnie na percepcję czasu, w którym się wydarza. Bodaj żadna ze sztuk nie łączy się tak ściśle ze strumieniem ludzkiej psychiki i emocjonalności. Czas jest więc namacalnym i wymiernym komponentem zjawiska dźwiękowego, a jego przestrzeń możemy określać za pomocą metafor, które są konstruowane dzięki ludzkiej wyobraźni w wielu indywidualnych doświadczeniach ${ }^{3}$.

Abradab, Powietrze, 048, Mystic Production 2018.

2 S. Reynolds, Retromania. Jak popkultura żywi się własna przeszłościa, przeł. F. Łobodziński, Kosmos Kosmos, Warszawa 2018, s. 42.

3 A. Chęćka-Gotkowicz, Ucho i umyst. Szkice o doświadczaniu muzyki, Słowo/Obraz Terytoria, Gdańsk 2012, s. 61-63. 


\section{Mechaniczne posłuchanie}

Wielu filozofów stawia pytanie o możliwości istnienia dzieła muzycznego i jego percepcji. Istnieje przekonanie (Roman Ingarden), że raz skomponowane dzieło jest niezależne od wszelakich procesów realnych. Warto zatem zastanowić się nad statusem ontologicznym tworów muzycznych utrwalonych na różnego rodzaju nośnikach w odróżnieniu od czysto fizycznego zjawiska rozchodzenia się dźwięku w powietrzu oraz muzycznych treści silnie obecnych w przestrzeni, a wyodrębnianych za pomocą urządzeń ${ }^{4}$. Ingarden wyraźnie stwierdza, że każde wykonanie utworu muzycznego w swoim podstawowym sensie jest zjawiskiem akustycznym, to, co słyszymy, wypełnia pewną przestrzeń, procesualny muzyczny ciąg wydarzeń przesuwa się linearnie w polu słyszenia, pojawiają się konstrukty dźwiękowe, które dynamicznie ustępują miejsca w centrum wrażenia słuchowego kolejnym 5 .

Chęć ujarzmienia dźwięku, schowania go w małym urządzeniu - pisze Radosław Sirko - towarzyszyła ludzkości od bardzo dawna ${ }^{6}$. Pismo, zapis nutowy, instrumenty muzyczne, telegraf i telefon - wszystkie te ogniwa pozwalały na przybliżanie się do sytuacji zachowania lub/i przekazania dźwięku. Jednak technologicznie „mowa stała się nieśmiertelna" po dokonanej przez Thomasa Edisona w 1877 roku udanej próbie rejestracji i odtworzenia głosu ${ }^{7}$. Było to możliwe dzięki twórczemu rozwinięciu pomysłu fonoautografu Édouarda-Léona Scotta de Martinville'a ${ }^{8}$, który używał rysika do śledzenia kształtu fali dźwiękowej na szklanym cylindrze, ale słabo nadawał się do odtworzenia dźwięku. Tym samym rozpoczęły się epoka foniczna ${ }^{10}$ oraz era słuchania kulturowego, które zdaniem Tomasza Misiaka zastąpiły słuchanie naturalne, uwzględniające kontekst pochodzenia dźwięku ${ }^{11}$. Odgłosy, których przyczyn nie widzimy, wpisują się w teorię akuzmatyki Pierre'a Schaeffera ${ }^{12}$, natomiast samo słuchanie uwikłane technologicznie stało się słuchaniem zapośredniczonym; XIX

4 J. Jusiak, Między zdarzeniem dźwiękowym a znaczeniem. Szkice z filozofii muzyki, Wydawnictwo Uniwersytetu Marii Curie-Skłodowskiej, Lublin 2013, s. 25-27.

$5 \quad$ R. Ingarden, Studia z estetyki, t. 2, PWN, Warszawa 1966, s. 174-178.

6 R. Sirko, Historia i prehistoria technicznego zapośredniczenia dźwięku, „Glissando. Magazyn o muzyce współczesnej” 2014, nr 23.

7 F.A. Kittler, Gramophone, Film, Typewriter, Stanford University Press, Palo Alto, CA 1999, za: „Scientific American” 1877, Read and Welch 1959.

8 Édouard-Léon Scott de Martinville starał się zgłębić fenomen słyszenia, chciał zobaczyć dźwięk, a także stworzyć urządzenie mogące wspomóc pamięć nowym typem pisma; zob. J. Jakubaszek, $W$ poszukiwaniu straconego głosu. Widzenie i styszenie przeszłości historycznej, w: J. Jakubaszek, R. Chymkowski (red.), Pongo. (Nie)widzialne, (Nie)styszalne, t. 7, grupakulturalna.pl, Katowice 2015, s. 26.

9 Earliest Voices: A Gallery from the Vincent Voice Library, http://www.historicalvoices.org/earliest_voices/ier.html (dostęp: 6.02.2019).

10 K. Janczewska-Sołomko, Zachować dźwięk, Biblioteka Narodowa, Warszawa 2000, s. 10.

11 T. Misiak, Kulturowe przestrzenie dźwięku, Bogucki Wydawnictwo Naukowe, Poznań 2013, s. 42.

12 P. Schaeffer, Akuzmatyka, w: Ch. Cox, D. Warner (red.), Kultura dźwięku. Teksty o muzyce nowoczesnej, Słowo/Obraz Terytoria, Gdańsk 2010, s. 107. 
wiek przyniósł także procesy związane z utowarowieniem dźwięku ${ }^{13}$. Zanim jednak odgłos udało się zapisać i skutecznie odtworzyć, muzyka funkcjonowała w innej przestrzeni. Ewa Kofin porządkuje sytuacje słuchania muzyki „na żywo” w czasach przednośnikowych, a są to przypadki:

1) gdy samemu potrafiło się grać czy śpiewać jakieś utwory, co wymagało zdobycia pewnych umiejętności, okupionych dość żmudną nauką, a w wypadku gry - jeszcze i kosztami zdobycia instrumentu; 2) gdy miało się znajomych muzyków, których można było do siebie zaprosić; 3) gdy mogło się zapłacić artyście czy artystom za występ we własnym salonie lub być gościem koncertu odbywającego się u znajomych; 4) gdy kupiło się bilet na koncert czy do opery albo do teatru na sztukę z muzyką; 5) gdy uczestniczyło się w jakichś uroczystościach czy też zabawie z udziałem muzyki; 6) gdy miało się w domu, lub gdzieś na niego natrafiało, instrument mechaniczny w rodzaju katarynki, pozytywki, pianoli, kurantu itd.; 7) gdy szło się do kościoła, gdzie muzyka była częścią obrzędu religijnego ${ }^{14}$.

Warto wspomnieć, że geneza literatury europejskiej, a co za tym idzie i muzyki jest dość wyjątkowa. Z początków twórczości większości ludów zachowały się jedynie „strzępy”. W wypadku Greków jest zgoła inaczej. U zarania dziejów Hellady wyłaniają się dwa wielkie, wspaniałe poematy: Iliada i Odyseja. Ich autorem był mityczny Homer, jak mówi legenda, niewidomy śpiewak, pochodzący z wyspy Smyrnos ${ }^{15}$. Trzeba zauważyć, że wszelkie gatunki literackie rozwijane w polis były nierozerwalnie połączone z muzyką. W Grecji istniała grupa zawodowych wyko-

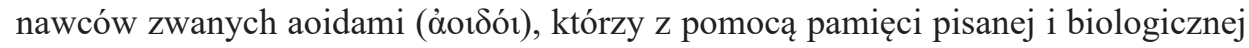
intensywnie uczestniczyli we wszelakich uroczystościach, a szczególnie byli zaangażowani w kult bogów. Program lokalnych świąt odbywających się regularnie zawierał imprezy muzyczne albo przynajmniej elementy muzyki: procesje ze śpiewem, tańce chórów, sympozjony czy rytualne hymny towarzyszące ofiarom. Źródła literackie przekazują istnienie tego rodzaju procesji podczas różnych uroczystości. Na wazach z okresu archaicznego widzimy takie pochody, które historycy dopasowują do różnych świąt: Panatejów, Oschoforiów czy miejskich Dionizjów w Atenach. Pierwotnie nośnikiem treści muzycznych był zatem człowiek ${ }^{16}$.

Urządzenia rejestrująco-odtwarzające znacznie zmodyfikowały praktykę słuchania i wykonywania muzyki, zostały wymyślone - pisze Jakub Jakubaszek - jako ekstensje ludzkiego aparatu poznawczego ${ }^{17}$. Dlaczego także wykonywania? Ponieważ urządzenia odtwarzające (gramofon, magnetofon, później także w inny sposób sampler) stały się pełnoprawnymi instrumentami, zaś sama forma albumu z muzyką zmodyfikowała kształt koncertów muzycznych. Początkowo nagrywanie muzyki

13 D. Antonik, Audiobook. Od brzmienia słów do głosu autora, ,Teksty Drugie” 2015, nr 5, s. 129.

14 E. Kofin, Muzyka wokół nas. Studium przeobrażeń recepcji muzyki w dobie elektronicznych środków jej przekazywania, Wydawnictwo Uniwersytetu Wrocławskiego, Wrocław 2012, s. 12.

15 Z. Kubiak, Literatura Greków i Rzymian, Świat Książki, Warszawa 1999, s. 11-16.

16 M.L. West, Muzyka starożytnej Grecji, przeł. A. Maciejewska, B. Kaziński, Homini, Kraków 2003, s. 28-29.

17 J. Jakubaszek, op. cit., s. 26. 
było reprodukcją koncertu ${ }^{18}$, jednak już od połowy XX wieku, kiedy praca studyjna zdominowała obszary muzyki popularnej, praktyka koncertowa zaczęła dążyć ku odtwarzaniu „na żywo” materiału zarejestrowanego na nośniku. Badacze dźwięku zaproponowali tym samym nową teoretyczną periodyzację zdarzeń uwikłanych w konteksty technologiczne. Simon Frith opracował kolejno: 1) etap ludowy - związany z muzyką graną na żywo oraz instrumentami muzycznymi; 2) etap artystyczny, charakterystyczny dla notacji nutowej oraz koncertów; 3) etap popularny powiązany już z rejestracją i odtwarzaniem dźwięku ${ }^{19}$. Chris Cutler z kolei wypunktował: muzyczną kulturę ludową, gdzie tworzenie i wykonywanie muzyki było ze sobą integralnie powiązane podobnie jak figura kompozytora i wykonawcy; kulturę klasyczno-artystyczną, której medium stanowiło zapis nutowy; oraz ostatnią - kulturę współzależną od rejestrowania i reprodukowania ${ }^{20}$. Proces nagrywania - pisze Anna Nacher - to składowa wielu czynników, między innymi pracy ludzi, techniki, procedury i okoliczności stanowiących układ, którego wynikiem jest nagranie ${ }^{21}$. Oddajmy jeszcze głos kompozytorowi Pawłowi Mykietynowi:

często się zastanawiam nad tym, czym muzyka jest dzisiaj, a czym była sto lat temu, zanim powstała fonografia, kiedy nie było żadnych nośników dźwięku. Żeby usłyszeć utwór muzyczny, trzeba było go sobie zagrać albo dotrzeć gdzieś, gdzie był wykonywany. Wyobrażam sobie, że sto pięćdziesiąt lat temu, kiedy ktoś usłyszał grajka w miarę sensownie grającego na skrzypcach, to było mistyczne przeżycie. A słuchanie na żywo kwartetu smyczkowego Mozarta było doświadczeniem kosmicznym. Natomiast dzisiaj, kiedy jesteśmy nieustannie atakowani dźwiękiem, koncert symfoniczny nas trochę nudzi ${ }^{22}$.

\section{Nośniki fizyczne i zmyślone chmury}

Dzięki nośnikowi muzyka stała się udomowiona, a obcowanie z nią intymne, prywatne - pisze Artur Szarecki ${ }^{23}$. Muzyka winna być przedstawiona i zapośredniczona - uważa z kolei Tomasz Misiak, a obie te formy łączą się w przestrzenie hybrydyczne. Przykładem tak rozumianych przestrzeni są między innymi: zapis nutowy, sala koncertowa, taśma magnetofonowa, płyta CD lub dysk komputera ${ }^{24}$. Jest to egzem-

18 Ch. Cox, D. Warner (red.), Kultura dźwięku..., op. cit., s. 150.

19 S. Frith, Sceniczne rytuały. O wartości muzyki popularnej, przeł. M. Król, Wydawnictwo Uniwersytetu Jagiellońskiego, Kraków 2011.

20 Ch. Cutler, O muzyce popularnej, przeł. I. Socha, Zielona Sowa, Kraków 1999.

${ }^{21}$ A. Nacher, Rejestracja audio i odtwórczość jako twórczość: efekt fonografu, „Kultura Współczesna. Dźwięk, Technologia, Środowisko" 2012, nr 1 (72), s. 1-2.

22 Muzyka będzie matematyka. Rozmowa z P. Mykietynem, w: R. Pawłowski, Bitwa o kulturę. \#Przyszłość, Teatr Stary w Lublinie - Wydawnictwo Krytyki Politycznej, Lublin-Warszawa 2015, s. 341-343.

${ }^{23}$ A. Szarecki, Ciało stuchające wobec zmiany nośników muzycznych, „Kultura Współczesna. Dźwięk, Technologia, Środowisko" 2012, nr 1(72), s. 119.

24 T. Misiak, Muzyczne gry z nośnikiem. Artystyczne strategie przekraczania medium, w: M. Parus, A. Trudzik (red.), Media jako przestrzenie muzyki, Wydawnictwo Naukowe Katedra, Gdańsk 2016, s. 133-134. 
plifikacja holistycznego ujęcia form zapośredniczenia, gdzie bierze się po uwagę tak odległe praktyki jak z jednej strony zapis nutowy, a z drugiej - wirtualną formę przechowywania muzyki na dyskach optycznych komputerów ${ }^{25}$. Co istotne, niniejszy tekst podejmuje tematykę rejestracji muzyki na nośnikach fizycznych i wirtualnych, zatem zapis nutowy nie jest tu brany pod uwagę. Ponadto artefakt z nagraną muzyką jest czymś więcej niż zapis nutowy, ponieważ rejestruje określoną chwilę - pisze Simon Reynolds, cytując Ariela Pinka ${ }^{26}$.

Muzyka może istnieć między nutami. Urządzenia cyfrowe, odtwarzacze i samplery rejestrują wszystkie elementy dostępnej nam audiosfery. Dzięki aparaturze możemy utrwalać i analizować komplikacje metryczno-melodyczne wymykające się zapisowi nutowemu, chociażby bogate sekwencje rytmiczne odgrywane na tabli w muzyce hinduskiej, brzmienie gitary Jimiego Hendrixa czy śpiew alikwotowy. Notacja $\mathrm{w}$ tradycji zachodniej stanowi zatem egzemplifikację wybranych, najważniejszych i konkretnych aspektów utworu o charakterze imperatywnym, a jej wykonanie staje się realizacją owych wytycznych ${ }^{27}$. Istotnym wątkiem w tym kontekście zdaje się status ontyczny utworu muzycznego i partytury. Roman Ingarden wyraża sprzeciw wobec pojmowania partytury jako czegoś fizycznego, widzi w niej system znaków szczególnego rodzaju, który uwidacznia się jedynie na bazie pewnych aspektów fizycznych (nuty w formie wydruku czy na ekranach i w programach do edycji kompozycyjnych). Partytura, na przykład Die Kunst der Fuge Jana Sebastiana Bacha, stanowi system znaków, które pojawiają się w jednakowy albo bardzo podobny sposób w dostępnych jej egzemplarzach. Dzieło muzyczne nie jest tożsame z partyturą ze względu na jednoczesne występowanie w tej jego egzemplifikacji zarówno czynników niematerialnych, jak i niepsychicznych. Zapis nutowy to system znaków powstający na drodze subiektywnych operacji i będący ich transcendentnymi wytworami, natomiast $\mathrm{w}$ stosunku do procesu ich dekodowania pozostaje transcendentnym jego przedmiotem. Pewien układ znaków czy sam znak może być identyfikowany z różnymi systemami, kodami czy sposobami rozumienia bądź oznaczania jako intersubiektywny przekaźnik. Tego rodzaju systemem znaczącym jest dla wykonawców partytura $^{28}$.

Ingarden rozróżnia pojęcie przedmiotu i wyglądu słuchowego o podłożu pewnych danych wrażeniowych. Wyglądy zależne są od czasu i przestrzeni, zarówno w sali koncertowej, jak i - śmiało można stwierdzić - w tramwaju, różnych źródeł dźwięku, plików mp3 o takim, a nie innym próbkowaniu, kolejnych wydań CD, choćby utworu Echoes (1971) grupy Pink Floyd, lub za pośrednictwem płyty winylo-

25 Pośród tak różnych nośników ciekawym ewenementem mogą być również taśmy perforowane, które były czymś pomiędzy zapisem nutowym a rejestracją dźwięku - służyły między innymi do odtwarzania muzyki w pianoli.

26 Reynolds odwołuje się do słów Ariela Pinka; zob. S. Reynolds, op. cit., s. 41.

27 N. Cook, Muzyka. Bardzo krótkie wprowadzenie, przeł. M. Łuczak, Prószyński i S-ka, Warszawa 2000, s. 67-68.

28 R. Ingarden, op. cit., s. 196-199. 
wej. Zmiany zachodzące w zawartościach wyglądów słuchowych są uwarunkowane przeobrażeniami w bazie wrażeniowych danych słuchowych i sposobem ich odbioru przez słuchacza, czyli określonym ujmowaniem. W zespoleniu tych dwóch przestrzeni następuje konkretyzacja dzieła muzycznego, odnoszona najczęściej do pewnego (ulubionego, badanego) wykonania. W uzmysłowieniu sobie tego fenomenu szalenie pomocny jest fonogram, kiedy po dwukrotnym wysłuchaniu dzieła w pełni odsłania się odrębność wykonania i jego konkretyzacji ${ }^{29}$. Kwestią oczywistą jawi się więc niejednorodność wykonań, z których każde jest w pewnym stopniu wyznaczane przez wykonawcę i jego indywidualne cechy, ale i położenie w czasie i przestrzeni, zastosowanie prawideł muzycznych, barwy tonów, tempa, szczegółów dynamiki, wyrazistości następujących po sobie motywów. Różnice objawiające się w realizacji tych komponentów są niemożliwe do zniesienia; nawet wtedy, kiedy frazy generowane są przez komputer (muzyka elektroniczna), konkretyzacja zawsze będzie odmienna. Ponadto każde urzeczywistnienie dzieła muzycznego jest jednoznacznie, pozytywnie określone jako złożone ze zróżnicowanych komponentów, które same podlegają podziałowi na cząstki niepodzielne - w muzyce europejskiej stanowią je półtony ${ }^{30}$.

Mimo kapitalnego znaczenia zapisu nutowego dla muzyki współcześnie pracuje się nad doskonalszymi formami graficznej reprezentacji dźwięku, które uwzględniałyby nie tylko niuanse brzmieniowe, ale także całą paletę nowych instrumentów, nie wyłączając komputera i samplera ${ }^{31}$. Zmiany, które obecnie staramy się zrozumieć, choć w innej postaci, miały także miejsce wcześniej w historii - w myśl an-archeologii Siegfrieda Zielinskiego, w końcu wiele współczesnych form zapośredniczania stanowi twórczą kontynuację, która ewoluowała przez wieki. Jednak sprawy związane z notacją muzyczną (zapisem nutowym) lepiej zostawić muzykologom, przykładowo - wpływ druku na muzykę szczegółowo omawia Paweł Gancarczyk w swojej książce ${ }^{32}$.

Jednak to nie fizyczne nośniki, ale właśnie sieciowa, cyfrowa i strumieniowa dystrybucja dźwięku nastręcza problemów, wręcz już natury definicyjnej. Współczesność podpowiada słuchaczowi możliwość dostępu do dźwięku wirtualnego, a więc teoretycznie pozbawionego nośnika. „Znika nośnik, wystarczy głośnik” - deklamuje Abradab, ale czy tak jest rzeczywiście? Czy nośnik zniknął, czy też po prostu oddalił się od słuchacza poza horyzont widzenia? W jednym $\mathrm{z}$ wywiadów wspomniany już Siegfried Zielinski zwrócił uwagę na fakt, iż w obszarach związanych z mediami używa się mylących pojęć. Wśród wielu wymienia między innymi chmury czy strumienie $^{33}$; badacz uważa podobne pojęcia za pusty wynalazek przemysłu. Jako

29 Ibidem, s. 176-177.

$30 \quad$ Ibidem, s. 178-179.

31 Więcej na ten temat - „Glissando. Magazyn o muzyce współczesnej” 2017, nr 32.

32 Zob. P. Gancarczyk, Muzyka wobec rewolucji druku. Przemiany w kulturze muzycznej XVI wieku, Wydawnictwo Naukowe Uniwersytetu Mikołaja Kopernika, Toruń 2011.

33 K. Szydłowski, S. Zielinski, Przeszłość jest nieskończonym zbiorem możliwości. Rozmowa z Siegfriedem Zielinskim o an-archeologii mediów, „Teksty Drugie” 2014, nr 3, s. 238. 
użytkownicy przyswoiliśmy rzeczone strumienie i chmury, wyobrażając sobie, że są wirtualną formą przechowania dźwięku, która może istnieć niejako bez fizycznego zakotwiczenia. Tymczasem wszystkie te wirtualne serwery w rzeczywistości są fizycznymi, namacalnymi urządzeniami, a tym samym - formą nośnika. Zatem nośnik nie zniknął, tylko odpowiednio się przeobraził i „oddalił” od słuchacza w stronę usługodawcy, który udostępnił urządzenia mogące, w tym przypadku, magazynować i udostępniać dźwięk. „Chmury”, „strumienie” i inne określenia sugerujące niefizyczność mogą powodować, że w społecznym odczuciu nośnik znika. Słuchacz nie musi trzymać w ręku kasety czy płyty, ale potrzebuje urządzeń faktycznie komunikujących się z innymi urządzeniami. Zatem nośnik z jednej strony stał się smartfonem, tabletem czy ,zwykłym” komputerem, a z drugiej - trochę dalej od słuchacza - serwerem lub po prostu urządzeniem gromadzącym dane.

\section{Przegrany kompakt}

Ewa Kofin zauważa, że w erze przednośnikowej muzyka w życiu człowieka pojawiała się sporadycznie, ale za to jej incydentalny odbiór był uważny, bardziej wyjątko$w^{34}$. Warto zauważyć, że badacze radia dochodzą do podobnych wniosków, kiedy przywołują początki „starego medium”, które gromadziło wokół siebie słuchaczy w czasie trwania interesującej audycji. Niemniej pojawienie się możliwości zapisu i odtworzenia dźwięku spowodowało także jego spowszednienie, a procesy cyfrowej dystrybucji - dalsze nim znużenie (dzięki formatom takim jak mp3 piosenki gromadziło się niemalże hurtowo; duże ilości, słaba jakość). Muzykę zapisaną na nośniku można było po prostu zignorować, gdyż nośnik mógł (ale nie musiał) pozbawić muzykę aury wyjątkowości, sytuację dodatkowo skomplikowało pojawienie się muzaka, który traktował dźwięk w sposób skrajnie funkcjonalny. Szczególnie dychotomia uwzględniająca muzykę graną na żywo oraz tę odtwarzaną z nośnika uwypuklała niezwykłość tej pierwszej. Podobnie sytuacja wyglądała w momencie, kiedy rynek muzyczny przeżywał rewolucję muzyki dystrybuowanej cyfrowo. Wówczas pojawiały się podobne argumenty przemawiające, tym razem, za fizycznym nośnikiem w kontrze do nagrania „niematerialnego”, pozbawionego artefaktów w postaci okładki, książeczki i jakiejś formy nośnika ${ }^{35}$. Robert Kuśmirowski mówi, że „w przypadku cyfrowych nośników szacunek do zespołu wydaje się jakby mniejszy,

34 E. Kofin, op. cit., s. 13.

35 Oczywiście okładkę można było ściągnąć i zapisać na dysku, jednak wraz z upowszechnieniem dystrybucji cyfrowej okładka przestała mieć większe znaczenie. Nie oznacza to, że obrazek towarzyszący muzyce zniknął. Współcześnie muzyka bardzo chętnie zestawiana jest z wideo - tendencja zakładająca publikowanie w sieci co jakiś czas teledysku wydaje się ważniejsza niż wydawanie całego albumu. Zwłaszcza że serwisy takie jak YouTube traktowane są jako platformy udostępniające muzykę, wideo streaming to 47\% spośród muzyki słuchanej w opcji on-demand; zob. Music Consumer Insight Report 2018, https://www.ifpi.org/news/IFPI-releases-2018-music-consumer-insight-report (dostęp: 22.03.2019). 
człowiek nawet nie wczytuje się w tę okładkę. Przy winylu czytało się całą okładkę i było mało" "36. Wśród argumentów przemawiających za nośnikiem dało się słyszeć również i te mówiące o szacunku dla płyty, za którą trzeba było zapłacić. Wszelkie fizyczne wydania zyskiwały wartość dodaną poprzez fakt, że słuchacz wydał na nie pieniądze - często były to duże kwoty. Dzisiaj podstawowe usługi strumieniowe są darmowe, nie wspominając o nadal dużym ,rynku” wymiany nielegalnych nagrań.

Wydaje się, że wśród dwudziestowiecznych nośników w najgorszej sytuacji jest obecnie płyta kompaktowa (CD); to przecież nośnik - ale cyfrowy. Reprezentuje dwa światy zapośredniczonego dźwięku: jako łącznik analogu (nośnik) z cyfrą (sposób zapisu) nie przynależy całościowo do żadnego z nich. Kaseta magnetofonowa jest „retro"37, a płyta winylowa - „,kultowa”. Oba nośniki mają silny wymiar semiotyczny.

Marcin Rychlewski widzi w długogrającej płycie winylowej podstawowy determinant formy twórczości, szczególnie rockowej, ale także jazzowej czy fusion drugiej połowy XX wieku. Wprowadza do swojej analizy pojęcie „concept albumu” i definiuje je jako kompletną całość, wykształconą na drodze eksperymentów The Beatles i Franka Zappy po 1966 roku. Płyta długogrająca staje się strukturą nacechowaną kompozytorsko i literacko, przestaje być zbiorem niepowiązanych ze sobą trywialnych piosenek o miłości (z których The Beatles słynęli w pierwszym okresie swej działalności). Badacz jako exemplum proponuje ważne dzieła w postaci The Dark Side of the Moon (1973) Pink Floyd, Sgt. Pepper's Lonely Heart Club Band (1967) The Beatles czy Days of Future Past (1967) Moody Blues. W monografii znajduje się także przykład płyty grupy Jethro Tull Thick as a Brick (1972), na której są jedynie dwa utwory (Thick as a Brick, part 1 oraz part 2), każdy z nich na jednej stronie winylowego krążka. Rychlewski buduje aparat pojęciowy - triadę semiotyczną (muzyka, słowo, obraz), której najdoskonalszą egzemplifikację upatruje w albumach konceptualnych. Korzystając z terminologii Edwarda Macana, można stwierdzić, że album Jethro Tull jest wieloczęściową suitą rockową, złożoną z mniejszych części, które samodzielnie mogą być postrzegane jako wieloczęściowe suity. Podobnie przedstawia się zawartość Wish You Were Here (1975) Pink Floyd, która obok piosenek zawiera dwie duże struktury o tym samym tytule Shine on You Crazy Diamond (part 1 oraz part 2). Pierwsza rozpoczyna album, a druga w sposób klamrowy go zamyka w granicach czarnego krążka ${ }^{38}$.

Płyta CD pojawiła się na rynku w latach 80 . XX wieku jako wygodna alternatywa dla słabych jakościowo kaset oraz wymagających i nietrwałych płyt winylowych. Była lekka, względnie tania, dysponowała dobrą dynamiką, kolejne odtwarzania nie

36 Wszyscy będziemy artystami. Rozmowa z R. Kuśmierowskim, w: R. Pawłowski, Bitwa o kulturę..., op. cit., s. 265.

37 Kaseta magnetofonowa stała się symbolem umieszczanym na koszulkach, torbach oraz okładkach wielu naukowych publikacji, między innymi: S. Reynolds, op. cit.; M. Major, P. Włodek (red.), Pomiędzy retro a retromania, Wydawnictwo Naukowe Katedra, Gdańsk 2018

38 M. Rychlewski, Rewolucja rocka. Semiotyczne wymiary elektrycznej ekstazy, Oficynka, Gdańsk 2011, s. $56-58$. 
powodowały zużycia materiału i straty jakości. Zapisany dźwięk był czysty - bez szumów kasety i winylowych trzasków - czyli tego, co w rezultacie stanowi o zjawiskowości analogowych poprzedników (zatem zabieg, który w założeniach miał słuchanie uczynić przyjemniejszym - brak zakłóceń - uwypuklił po czasie charakter nośnika cyfrowego jako medium odartego z wyjątkowości). Jednak płyta, po udanej dla niej dekadzie, musiała powoli kapitulować wobec postępującej dominacji formatów cyfrowych w rodzaju mp3 oraz sieciowej dystrybucji. Kolekcjonerzy nagrań, którzy zamienili kasety i płyty winylowe na płytę CD, w obliczu cyfrowej rewolucji lat 90. zostali z nośnikiem, który stopniowo tracił na znaczeniu. Gromadzona i kolekcjonowana przez lata muzyka nagle stała się ogólnodostępna. Atrybuty kompaktu przestały być wyróżniające; nagle płyta zaczęła zabierać miejsce na półce, „czysty” dźwięk cyfrowy oferowały już formaty dystrybuowane sieciowo, zaś sam nośnik wcale nie okazał się trwały i niezniszczalny. Do tego podano w wątpliwość wierność zapisu cyfrowego, między innymi niewystarczającą pojemność płyty CD (szczególnie pierwszych nośników), procesy związane z kwantyzacją dźwięku oraz fakt, że zapis analogowy jest bliższy rzeczywistości (słuchacz również jest analogowy). Zatem cyfrowość kompaktu współcześnie stanowi bardziej wadę niż zaletę, a same zbiory przestały mieć wartość, poza czysto kolekcjonersko-sentymentalną. Jednak analizując retromanię względem nośników dźwięku, można założyć, że również płyta CD stanie się nośnikiem poszukiwanym i kompletowanym. Krzysztof Pietraszewski ocenia, że kompakt wróci na fali resentymentu w ciągu dwóch lub trzech dekad ${ }^{39}$.

W ujęciu semiotycznym można dostrzec różnorakie konsekwencje wypływające z wprowadzenia płyty kompaktowej. Poprawiona zostaje jakość dźwięku i zwiększa się zasobność nośnika w czas - pierwotnie do 74 minut; choć struktura całościowa „srebrnego krążka” w pewnym stopniu zachowuje cechy triady semiotycznej swej poprzedniczki, to w sposób istotny zaburza jej (samej triady) konstrukcję. Winyl gromadził zestaw piosenek przeznaczony jedynie dla samego siebie, w reedycjach kompaktowych pojawiają się tak zwane utwory dodatkowe (ang. bonus tracks), czyli po prostu alternatywne wersje kompozycji zamieszczonych w zestawie podstawowym. Należy zauważyć, że z konieczności utwory dodatkowe w wydaniach jazzowych prezentują lepszą jakość niż podobne w rockowych, o czym Rychlewski nie wspomina. Wynika to z odmiennych technik realizacji nagrań i umiejętności instrumentalistów, zwłaszcza w latach 60. XX wieku. Badacz dostrzega wagę ,instytucji” nagrywarki CD w latach 90., która powoduje istotną erozję, a w konsekwencji prawie całkowity zanik starannie wypracowanego pojęcia (triady semiotycznej). W polu percepcji pojawiają się wytworzone amatorsko okładki lub samodzielne opisy płyt, zanika wkładka (z ang. inlay), która zawierała bardzo intersujące treści dla pasjonatów i badaczy ${ }^{40}$.

39 K. Pietraszewski, Muzyka nośnika, „Glissando. Magazyn o muzyce współczesnej” 2017, nr 32, s. 49. 


\section{Kolekcjonerstwo wirtualne}

W XX wieku obieg dzieł sztuki - pisze Noël Carroll - uległ zapośredniczeniu dzięki technologii, a przede wszystkim w ramach produkcji masowej ${ }^{41}$. Nośnik jako produkt musiał zmierzyć się z atakami, które upatrywały w nim zagrożenie dla sztuki - jej wartości i autentyczności, miał być też przyczyną regresu słuchania, egalitarnym fetyszem, który zaniósł sztukę „,pod strzechy”. Muzyka mogła być multiplikowana w milionach egzemplarzy. Kiedy jednak nośnik dał się zrozumieć i udomowić, zaczęto go kolekcjonować. Jako element zbioru zyskał zupełnie nowy wymiar, często oderwany od faktycznej dźwiękowej zawartości; Simon Reynolds pisze o kolekcjonerach, którzy dbają o zbiory muzyczne jak o zabytkowe monety, znaczki czy antyki - fetyszyzując zarówno formaty, jak i opakowania ${ }^{42}$. W tym rozumieniu - zbierania muzycznych artefaktów - kolekcjonerstwo wydaje się niezagrożone. Mimo ewolucji procesów dystrybucji fizyczny nośnik posiadający wartość inną niż tylko sentymentalna lub wartość wynikającą po prostu z zawartości staje się częścią zbioru dumnego posiadacza. Inny aspekt dotyczy jakości samego dźwięku - audiofilia, która objawiła się w dzisiejszym kształcie w latach 70. XX wieku³ ${ }^{43}$, bardzo niechętnie i z dużą nieufnością przyjęła wirtualne formaty muzyczne. Szczególnie początki takiego sposobu wymiany plików, które operowały głównie na słabej jakości formatach, zniechęciły entuzjastów dobrego dźwięku. Współcześnie sytuacja ulega dynamicznej poprawie szybkość transferu oraz pojemność dysków pozwalają na słuchanie muzyki cyfrowej o wyższej klasie jakości dźwięku.

W momencie pojawienia się formatów, które mogły być swobodnie przesyłane między komputerami użytkowników sieci, kolekcjonerstwo nagrań przybrało wirtualną formę. Słuchacze wymieniali się muzyką, gromadząc ją na dyskach komputerów, licząc tym samym swe kolekcje nie w sztukach, ale w terabajtach. Początkowo, wobec stosunkowo niewielkiej pojemności dysków oraz najczęściej nielegalnego procederu udostępniania, muzyka zgrywana była na płyty $\mathrm{CD}$, co z kolei umożliwiały wspomniane nagrywarki, które podobnie jak wcześniej magnetofony dwukasetowe zrewolucjonizowały rynek. Kaseta magnetofonowa rozpoczęła rewolucję w zakresie praktyk komunikacyjnych, była kontrkulturowa, odbierała wielkim wytwórniom monopol pozwalający na kontrolowanie rynku muzycznego ${ }^{44}$. Nagrywarka płyt CD kontynuowała tę rewolucję, przenosząc dźwięk w XXI wiek, jakość przegrywanej muzyki (czy raczej: kopiowanej) nie musiała być stratna względem matrycy. Był to

${ }_{41}$ N. Carroll, Filozofia sztuki masowej, przeł. M. Przylipiak, Słowo/Obraz Terytoria, Gdańsk 2011, s. $12-13$.

$42 \quad$ S. Reynolds, op. cit., s. 139.

43 B. Chaciński, Wyż nisz. Od alterglobalistów do zośkarzy. 55 matych kultur, Znak, Kraków 2010, s. 24.

44 Zob. M. Żakowski, Kaseta magnetofonowa, czyli muzyka 2.0 w wersji beta, w: W. Godzic, M. Żakowski, Gadżety popkultury. Społeczne życie przedmiotów, Wydawnictwa Akademickie i Profesjonalne, Warszawa 2007. 
więc jakościowy postęp na tle taśmy. Kariera pustej (lub czystej) płyty CD nie trwała jednak długo, została zastąpiona przez nośniki typu pendrive oraz, przede wszystkim, możliwość przesyłania treści przez sieć. W odpowiednim czasie zaczęły pojawiać się małe urządzenia odtwarzające formaty cyfrowe, nowym walkmanem został iPod, obecnie zaś wszystkie te praktyki przeniosły się do smartfonów.

Wydawałoby się, że wobec dostępu do muzyki na żądanie (on-demand) formy kolekcjonowania na dyskach optycznych lub nagrywalnych nośnikach przestaną być popularne. Okazuje się jednak, że słuchacz-użytkownik jest zbieraczem, wskazuje na to zjawisko stream-rippingu (czyli dalszego archiwizowania), które dotyczy $32 \%$ użytkowników (23\% używa P2P, a 17\% poszukuje treści poprzez naruszające prawo wyszukiwarki) ${ }^{45}$. Posiadanie muzyki ,na dysku” jest nadal ważne, nawet jeżeli jest to tylko nośnik danych, który indeksuje tysiące albumów, będących po prostu kolejnymi numerami w pokaźnych katalogach. Można także kolekcjonować muzykę na udostępnionych serwerach poprzez układanie własnych playlist czy porządkowanie nagrań za pomocą prostych narzędzi udostępnianych przez serwisy typu Spotify czy Tidal. Pokazywanie własnej, stojącej na półce kolekcji zostało zastąpione przez udostępnianie sporządzanych list piosenek oraz upublicznianie w serwisach strumieniowych lub portalach społecznościowych. Rafał Księżyk pisze o playliście jako o muzycznym fetyszu, który zastąpił płytę. Prywatne playlisty są elementem autokreacji, kanałem porozumienia, który „sprowadza muzykę do znaku określającego indywidualność, do gestu własnego wyboru, będącego jednocześnie zaproszeniem do komunikacji. Playlista to sposób na uchwycenie w sieci odrobiny własnej czasoprzestrzeni” ${ }^{46}$. Współcześni DJ-e amatorzy proponują playlisty w formie zestawów piosenek, również własne miksy - filtry i nakładki na bazy dźwiękowe strumieniowych usługodawców. W tym sensie swoimi medialnymi praktykami przypominają dziennikarzy muzycznych.

Marcin Rychlewski proponuje kategorię „rozproszonego” odbioru, która manifestuje się w stylistyce muzyki popularnej choćby przez unieważnienie klasycznych opozycji (np. art rock - hard rock). W XXI wieku cechy gatunkowe pozostają jedynie konwencjami, co ciekawe, mogą być unifikowane przez współczesnych artystów i składać się na postmodernistyczny hybrydyczny całokształt. „Rozproszenie” odbioru dotyka również kwestii nośnika; badacz twierdzi, że nastąpiło przejście od „kultury longplaya” do „kultury mp3 i iPoda” ${ }^{47}$. Nasza analiza włącza w tę perspektywę jeszcze tzw. chmury i popularne obecnie serwisy streamingowe. Starannie wypracowana triada semiotyczna nie ulega całkowitej entropii, zostaje zachowana w teledyskach, a także na koncertach oraz w semantycznych segmentach odtwarzaczy lub interfejsach web playerów. Marginalizacja fizycznych nośników spowodowała odseparowanie struktury triady od „skupiającego” fizycznego nośnika. Ekspansja in-

45 Music Consumer Insight Report 2018, op. cit.

46 R. Księżyk, Wywracanie kultury. O dandysach, hipsterach i mutantach, Wydawnictwo Czarne, Wołowiec 2018, s. 21-22.

47 M. Rychlewski, op. cit., s. 200-206. 
ternetu jeszcze to oderwanie pogłębia, obecnie treści muzyczne oglądane i słuchane są głównie w sieci. W tym kontekście warto przypomnieć metodę marketingową zastosowaną przez zespół Radiohead przy promocji albumu In Rainbows (2007), kiedy to za pośrednictwem strony internetowej można było nabyć nagrania w formie plików. Zespół rozważał całkowitą rezygnację z nośników fizycznych, jednak ostatecznie pojawiały się wersje kompaktowe ${ }^{48}$. Ostatni album, A Moon Shaped Pool (2016), również wydano na „kompakcie” i „winylu”. Istnienie muzyki w powietrzu stanowi o wygodzie słuchaczy. Nośnik fizyczny w kolekcjach pasjonatów staje się elementem ,retro rytuału” i pozwala na kontakt z realnym artefaktem, o wartości obwoluty nie wspominając.

\section{Fast listening}

Nadmiar muzyki, którą w łatwy sposób można wyprodukować (sic!) oraz rozesłać sieciowymi kanałami, może także powodować spadek jej wartości w społecznym odczuciu oraz w zindywidualizowanym przypadku konkretnego słuchacza. Muzyka nie jest zdobywana, w większości przypadków standardowej dystrybucji jest także darmowa. To inna sytuacja wobec tej, w której trzeba było wydać na fizyczny nośnik określoną kwotę. Zdaniem Simona Reynoldsa już sam ten fakt powodował przymus przesłuchania zawartego na płycie materiału ${ }^{49}$. Ilość muzyki docierającej do uszu słuchacza, zarówno tej dobieranej w sposób intencjonalny, jak i w formie zupełnie przypadkowego muzaka, może spowodować zobojętnienie, rodzaj audytywnego wypalenia $^{50}$. Mechanizm uwzględniający komplementarny proces powstawania muzyki oraz czas jej dotarcia do odbiorcy uległ dramatycznemu przeobrażeniu. Dystrybucja sieciowa zmodyfikowała figurę albumu muzycznego, który przestał być kluczowym elementem konstytuującym muzyka i definiującym jego pozycję na rynku - obecnie ważniejsza jest permanentna łączność ze słuchaczami. Owa łączność manifestuje się choćby w postaci wypuszczanych w - mniej więcej - równych odstępach czasowych piosenek, często zobrazowanych teledyskiem. Oprócz tego artysta korzysta z nowomedialnych narzędzi społecznościowych, dzięki którym komunikuje się z fanami, podsycając zainteresowanie. Powoduje to wrażenie bliskości, intymności wręcz, jednak może odzierać z wyjątkowości relację artysta-słuchacz. Ten pierwszy przestaje być nadludzkim zjawiskiem, niedostępną i tajemniczą gwiazdą, widywaną tylko w rytuałach sali koncertowej, podczas misterium koncertu, i staje się codziennością, wirtualnym sąsiadem, którego prozaiczne poczynania można obserwować na żywo via internet.

Nadmiar zarejestrowanej muzyki powoduje, że staje się ona wtórna wobec koncertów na żywo. Pomijając szczegółowe problemy nakreślone w koncepcji „naży-

48 Ibidem, s. 206-208.

49 S. Reynolds, op. cit., s. 183.

$50 \quad$ Ibidem, s. 186. 
wości” Philipa Auslandera, również i ten badacz zwraca uwagę, że przemysł koncertowy, głównie w aspekcie ekonomicznym, wobec dominacji darmowej muzyki strumieniowej ponownie stawia na formę koncertowania jako źródła rekompensaty finansowej ${ }^{51}$. Simon Reynolds zauważa wręcz, że muzyka nagrywana może być przygotowana niedbale. Jako egzemplifikację podaje przypadki wykonawców muzyki elektronicznej, których czas zagospodarowany jest głównie długimi trasami koncertowymi. Wówczas płyty stają się elementem dodanym, a nie wiodącym, w całym uniwersum kariery muzycznej ${ }^{52}$. Z drugiej strony - jak zauważają w rozmowie Filip Szałasek i Marek J. Sawicki - sieć umożliwiła nieskrępowany dostęp do archiwów muzycznych, co przełożyło się na powtórne zainteresowanie zapomnianą muzyką, a tym samym możliwość dopisywania nowych kontekstów oraz szerszego spojrzenia na muzykę popularną ${ }^{53}$. O nagrywaniu jako przemijającym epizodzie dywagują Michał Libera i Daniel Muzyczuk ${ }^{54}$, którzy proponują potraktowanie XXI wieku jako ostatniej fazy wybrzmienia. Argumentują, że przecież ani Scott de Martinville, ani Thomas Edison czy Pierre Schaeffer nie chcieli stać się archiwistami dźwięku. W świetle tej koncepcji i przełożeniu jej na przyjętą w niniejszym tekście perspektywę muzyka uwalnia się nie tylko od nośnika, ale także od procesów rejestracji. Zatem jej powrót do powietrza byłby kompletny, ponieważ nie musiałby oznaczać powrotu do powietrza pełnego bezprzewodowej komunikacji, ale do takiego, które istniało, zanim zdołano uchwycić dźwięk, nagrywając go.

\section{Powietrze jako nośnik}

Nicolai Hartmann proponuje trojakie rozróżnienie bytu duchowego - osobowego, obiektywnego i zobiektywizowanego. Pierwszy dotyczy człowieka jako osoby zdolnej do ujmowania, doświadczania i pojmowania świata oraz do aktywnego wprowadzania w nim zmian. Duch obiektywny jest z natury ponadjednostkowy i wyraża wartości oraz treści wspólnotowe, przejawiające się w rzeczywistości. Duchem zobiektywizowanym niemiecki filozof określa utrwaloną w nośniku materialnym zawartość duchową. Tego rodzaju ufundowanie pozwala istnieć dziełu niezależnie od jego twórcy. Myśliciel twierdzi, że podstawę ontyczną utworu stanowi zawsze materialny nośnik realny, co ciekawe, w dobie jego wirtualizacji coraz rzadziej fizyczny. Leszek Kopciuch odnajduje w obrębie Hartmannowskich koncepcji pogląd, że w zależności od tego, czy mamy do czynienia z partyturą, wykonaniem czy wykonaniem zarejestrowanym, w inny sposób przebiegną poszukiwania konkretu sta-

51 P. Auslander, Na żywo czy...?, „Didaskalia. Gazeta Teatralna” 2012, nr 107, s. 19-20.

52 S. Reynolds, op. cit., s. 182.

53 F. Szałasek, Jak pisać o muzyce. O wolnym stuchaniu, rozmowa z M.J. Sawickim, Wydawnictwo W podwórku, Gdańsk 2015, s. 106-107.

54 M. Libera, D. Muzyczuk, Upadek nagrywania, w: A-I-R Sanatorium Dźwięku, Sokołowsko 2016, program. 
nowiącego fundament bytowy zjawiska muzycznego. W tym artykule z konieczności staramy się tego typu materialną podstawę odnaleźć dla zarejestrowanych wykonań, ale i owoców pracy producentów. Sam Hartmann utożsamiał pełnoprawne dzieło muzyczne z wykonaniem filharmonicznym, a za swego rodzaju „nośnik” (fundament ontyczny) uważał akustyczne zjawisko fizyczne występujące w powietrzu ${ }^{55}$.

Maksymilian Kapelański zwraca uwagę na charakterystyczne odgłosy nośników - trzaskanie płyty długogrającej, szum taśmy magnetofonowej, ale także twardy dźwięk płyt kompaktowych czy jednostajny szum komputerów podczas odtwarzania zapisanego na dyskach dźwięku ${ }^{56}$. Zatem dysk optyczny, zarówno ten w komputerze osobistym, jak i w formie serwera, zostaje zaliczony w poczet nośników. Oznacza to, że wszystkie te „chmury” i „strumienie” stanowią tylko efektowną przenośnię - dokładnie tak jak przedstawił to Siegfried Zielinski. Nośnik nie znika, jest tylko konsekwentnie odsuwany od słuchacza. To realizowanie idei opisanej jako celestial jukebox - natychmiastowy dostęp do wielkiej bazy muzycznej. Jak jednak przytomnie zauważa Hyojung Sun, przejęcie bazy muzycznej przez usługodawców może prowadzić do ponownej kontroli rynku ${ }^{57}$. Zatem poprzez skuteczne usuwanie nośnika - a raczej zabieranie go z rąk słuchacza - muzyka wraca pod jurysdykcję największych graczy na rynku muzycznym. To przejęcie kontroli „,na miękko”, kiedy daje się słuchaczowi teoretycznie nieograniczony wybór, który w praktyce oznacza także instytucjonalną władzę nad dźwiękiem. Ponadto autonomia wyboru staje się iluzoryczna wobec propozycji algorytmicznych, które stanowią rdzeń działania największych serwisów muzycznych ${ }^{58}$.

W toku poszukiwania nośnika uznać można zatem, że ów cały czas istnieje, nie znika. Z drugiej strony, wobec wirtualizacji - tej faktycznej i pozornej - ostatecznym nośnikiem jest powietrze. Bez niego i tak nie słyszelibyśmy dźwięku. Muzyka wraca do powietrza jako do swego pierwotnego nośnika, jednak powietrze to wypełnione jest formą bezprzewodowej komunikacji, która jednak zakotwiczona jest w fizycznych urządzeniach. Taki powrót rozpatrywać można przez pryzmat technologii. Muzyka wykonywana na tradycyjnych instrumentach lub śpiewana wolna jest od obciążeń technicznych, a jej nośnikiem są wykonawca i powietrze.

55 L. Kopciuch, Dzieło muzyczne w kontekście ontologicznego stratalizmu Nicolaia Hartmanna, w: K. Lipka (red.), Muzyka i filozofia I. Refleksje, konteksty, interpretacje, Wydawnictwo Uniwersytetu Muzycznego Fryderyka Chopina, Warszawa 2017, s. 51-65.

${ }_{56}$ M. Kapelański, Glenn Gould: cisza, fonosfera i muzyka w odległym zapisie, „Glissando. Magazyn o muzyce współczesnej” 2017, nr 32, s. 32.

57 H. Sun, Paradox of Celestial Jukebox: Resurgence of Market Control, „Creative Industries Journal” 2019 , vol. 12 , iss. 1 , s. 105-124.

58 S. Nożyński, DJ Algorytm - cyfrowa sugestia muzyczna jako substytut własnego wyboru, Neodidagmata 36/37, Wydawnictwo Naukowe UAM, Poznań 2018. 


\section{Bibliografia}

Abradab, Powietrze, 048, Mystic Production, 2018.

Antonik D., Audiobook. Od brzmienia słów do głosu autora, „Teksty Drugie” 2015, nr 5.

Auslander P., Na żywo czy...?, „Didaskalia. Gazeta Teatralna” 2012, nr 107.

Carroll N., Filozofia sztuki masowej, przeł. M. Przylipiak, Słowo/Obraz Terytoria, Gdańsk 2011.

Chaciński B., Wyż nisz. Od alterglobalistów do zośkarzy. 55 małych kultur, Znak, Kraków 2010.

Chęćka-Gotkowicz A., Ucho i umyst. Szkice o doświadczaniu muzyki, Słowo/Obraz Terytoria, Gdańsk 2012.

Cook N., Muzyka. Bardzo krótkie wprowadzenie, przeł. M. Łuczak, Prószyński i S-ka, Warszawa 2000.

Cox Ch., Warner D. (red.), Kultura dźwięku. Teksty o muzyce nowoczesnej, Słowo/Obraz Terytoria, Gdańsk 2010.

Cutler Ch., O muzyce popularnej, przeł. I. Socha, Zielona Sowa, Kraków 1999.

Earliest Voices: A Gallery from the Vincent Voice Library, http://www.historicalvoices.org/ earliest_voices/ier.html (dostęp: 6.02.2019).

Frith S., Sceniczne rytuały. O wartości muzyki popularnej, przeł. M. Król, Wydawnictwo Uniwersytetu Jagiellońskiego, Kraków 2011.

Gancarczyk P., Muzyka wobec rewolucji druku. Przemiany w kulturze muzycznej XVI wieku, Wydawnictwo Naukowe Uniwersytetu Mikołaja Kopernika, Toruń 2011.

„Glissando. Magazyn o muzyce współczesnej” 2017, nr 32.

Ingarden R., Studia z estetyki, t. 2, PWN, Warszawa 1966.

Jakubaszek J., W poszukiwaniu straconego głosu. Widzenie i słyszenie przeszłości historycznej, w: J. Jakubaszek, R. Chymkowski (red.), Pongo. (Nie)widzialne, (Nie)styszalne, t. 7, grupakulturalna.pl, Katowice 2015.

Janczewska-Sołomko K., Zachować dźwięk, Biblioteka Narodowa, Warszawa 2000.

Jusiak J., Między zdarzeniem dźwiękowym a znaczeniem. Szkice z filozofii muzyki, Wydawnictwo Uniwersytetu Marii Curie-Skłodowskiej, Lublin 2013.

Kapelański M., Glenn Gould: cisza, fonosfera i muzyka w odległym zapisie, „Glissando. Magazyn o muzyce współczesnej” 2017, nr 32.

Kittler F.A., Gramophone, Film, Typewriter, Stanford University Press, Palo Alto, CA 1999.

Kofin E., Muzyka wokół nas. Studium przeobrażeń recepcji muzyki w dobie elektronicznych środków jej przekazywania, Wydawnictwo Uniwersytetu Wrocławskiego, Wrocław 2012.

Kopciuch L., Dzieło muzyczne w kontekście ontologicznego stratalizmu Nicolaia Hartmanna, w: K. Lipka (red.), Muzyka i filozofia I. Refleksje, konteksty, interpretacje, Wydawnictwo Uniwersytetu Muzycznego Fryderyka Chopina, Warszawa 2017.

Księżyk R., Wywracanie kultury. O dandysach, hipsterach i mutantach, Wydawnictwo Czarne, Wołowiec 2018.

Kubiak Z., Literatura Greków i Rzymian, Świat Książki, Warszawa 1999.

Libera M., Muzyczuk D., Upadek nagrywania, w: A-I-R Sanatorium Dźwięku, Sokołowsko 2016, program.

Major R., Włodek P. (red.), Pomiędzy retro a retromania, Wydawnictwo Naukowe Katedra, Gdańsk 2018. 
Misiak T., Kulturowe przestrzenie dźwięku, Bogucki Wydawnictwo Naukowe, Poznań 2013.

Misiak T., Muzyczne gry z nośnikiem. Artystyczne strategie przekraczania medium, w: M. Parus, A. Trudzik (red.), Media jako przestrzenie muzyki, Wydawnictwo Naukowe Katedra, Gdańsk 2016.

Music Consumer Insight Report 2018, https:/www.ifpi.org/news/IFPI-releases-2018-music-consumer-insight-report (dostęp: 22.03.2019).

Muzyka będzie matematyką. Rozmowa z P. Mykietynem, w: R. Pawłowski, Bitwa o kulturę. \#Przyszłość, Teatr Stary w Lublinie - Wydawnictwo Krytyki Politycznej, Lublin-Warszawa 2015.

Nacher A., Rejestracja audio i odtwórczość jako twórczość: efekt fonografu, „Kultura Współczesna. Dźwięk, Technologia, Środowisko" 2012, nr 1 (72).

Nożyński S., DJ Algorytm - cyfrowa sugestia muzyczna jako substytut własnego wyboru, Neodidagmata 36/37, Wydawnictwo Naukowe UAM, Poznań 2018.

Pietraszewski K., Muzyka nośnika, „Glissando. Magazyn o muzyce współczesnej” 2017, nr 32.

Reynolds S., Retromania. Jak popkultura żywi się własna przeszłościa, przeł. F. Łobodziński, Kosmos Kosmos, Warszawa 2018.

Rychlewski M., Rewolucja rocka. Semiotyczne wymiary elektrycznej ekstazy, Oficynka, Gdańsk 2011.

Schaeffer P., Akuzmatyka, w: Ch. Cox, D. Warner (red.), Kultura dźwięku. Teksty o muzyce nowoczesnej, Słowo/Obraz Terytoria, Gdańsk 2010.

Sirko R., Historia i prehistoria technicznego zapośredniczenia dźwięku, „Glissando. Magazyn o muzyce współczesnej" 2014, nr 23.

Sun H., Paradox of Celestial Jukebox: Resurgence of Market Control, „Creative Industries Journal" 2019, vol. 12, iss. 1.

Szałasek F., Jak pisać o muzyce. O wolnym stuchaniu, rozmowa z M.J. Sawickim, Wydawnictwo W podwórku, Gdańsk 2015.

Szarecki A., Ciało słuchające wobec zmiany nośników muzycznych, „Kultura Współczesna. Dźwięk, Technologia, Środowisko" 2012, nr 1 (72).

Szydłowski K., Zielinski S., Przeszłość jest nieskończonym zbiorem możliwości. Rozmowa z Siegfriedem Zielinskim o an-archeologii mediów, „Teksty Drugie” 2014, nr 3.

West M.L., Muzyka starożytnej Grecji, przeł. A. Maciejewska, B. Kaziński, Homini, Kraków 2003.

Wszyscy będziemy artystami. Rozmowa z R. Kuśmierowskim, w: R. Pawłowski, Bitwa o kulturę. \#Przyszłość, Teatr Stary w Lublinie - Wydawnictwo Krytyki Politycznej, Lublin-Warszawa 2015.

Żakowski M., Kaseta magnetofonowa, czyli muzyka 2.0 w wersji beta, w: W. Godzic, M. Żakowski, Gadżety popkultury. Społeczne życie przedmiotów, Wydawnictwa Akademickie i Profesjonalne, Warszawa 2007. 